\title{
Self-directed pharmacotherapy learning to fifth-year pharmacy students in Spain
}

\author{
Idoya Beltrán Gárate and Guadalupe Beitia Berrotarán*
}

Department of Pharmacology and Toxicology, School of Pharmacy, University of Navarra, Pamplona, Spain.

\begin{abstract}
Pharmacy students have a difficulty in implementing the theoretical pharmacotherapy knowledge into practice, during their Advanced Pharmacy Practice Experiences (APPEs). The objective of this work was to evaluate the effectiveness of a teaching tool to guide students' self-directed pharmacotherapy learning. Students checked their own knowledge about: generic name, drug class, indication, dosage, potential adverse reactions and interactions, of 10 prescription drugs per week, during six months of practical training. Students recorded a self-assessment of their level of knowledge of prescription drugs using an answer sheet. The effectiveness was determined by a pharmacotherapy knowledge test at the beginning and end of the APPE. Thirty two students who set up this exercise were evaluated and compared to control group $(n=30)$. Results showed improvement between the intervention and control students' pre-test and post-test pharmacotherapy knowledge $(p=0.001)$. Additionally, student learning development was measured as the percentage of correct answers, related to students' level of pharmacotherapy knowledge, filled out using the answer sheet, in the course of the 6 months of APPE. Analysis of 8 answer sheets showed an increment of pharmacotherapy learning during six months. "Indication" and "drug class" displayed the biggest percentage of correct answer in the first month, while "dosage", "interactions" and "adverse reactions" showed the least percentage of correct answer at this time. Besides, this analysis allowed the identification of commonly prescription drugs, both in community pharmacy and hospital pharmacy. The overall students 'opinion was very positive. Designed method improved student's self-directed learning, identifying their own knowledge in pharmacotherapy, during APPE.
\end{abstract}

Key words: Advanced Pharmacy Practice Experience, Pharmaceutical Care, Pharmacotherapy, Self-directed learning, Undergraduate Pharmacy Student.

\section{INTRODUCTION}

Educational standards set forth by National Agency for Quality Assessment and Accreditation of Spain require schools of pharmacy to ensure student competencies in the practice of pharmaceutical care.

Pharmaceutical care is a patient-centered practice that results in positive pharmacotherapeutic outcomes for patients through identification, resolution, and prevention of drug-related problems, as well as encouraging proper use of medications. The goal of pharmaceutical care is to optimize the patient's health-related quality of life. ${ }^{1}$

The school of pharmacy at University of Navarra has included the subject "Pharma-
Submission Date : 17-09-2014 Revision Date : :30-09-2014 Accepted Date :23-12-2014

ceutical care" in its curriculum, with communication modules and practice laboratories being created to facilitate the implementation of pharmacy practice skills. Besides, Spanish Advanced Pharmacy Practice Experience (APPE) subject is a six-month pharmacy practice at the end of the 5-year degree in pharmacy. The subject offers a practical experience in a community pharmacy or in a hospital pharmacy, under the supervision of a preceptor-pharmacist, where students encounter real patients and work with medical prescriptions in order to gain pharmaceutical care skills. Therefore, students are expected to combine their knowledge obtained from
DOI: 10.5530/ijper.49.1.2 Correspondence Address Dr.Guadalupe Beitia University of Navarra, Faculty of Pharmacy,

Department of Pharmacology and Toxicology, Irunlarrea Street, 1, 31008 Pamplona,

Navarra, Spain.

E-mail: gbeitia@unav.es

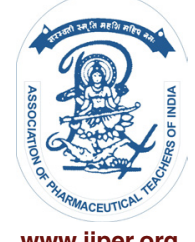

www.ijper.org 
different subjects and to develop problem-solving abilities in therapeutics.

Students, during their APPEs, are located across the state at several volunteer training centers. Further, the instruction that these students receive from preceptors depends on a number of factors that vary from center to center and change from day to day, including the assertiveness of the students, the amount and quality of interactions between the student and preceptor, the preceptor's/pharmacist's knowledge and teaching skills, and the availability of quality training time.,3

Many would argue that teaching pharmacy students to identify, resolve and prevent drug related problems according to the pharmaceutical care processes, is currently the greatest challenge in modern undergraduate education. Unfortunately, despite the increasing amount of attention being given to the teaching of pharmaceutical care, educational programs are still not optimal in many pharmacy schools. Nowadays, many graduates still feel insufficiently prepared to assume patient-centered care responsibilities after graduation. ${ }^{4,5}$

Pharmacy students are often overwhelmed by the large number of drugs that they hear about and encounter during their practical training. For each drug or drug class, students might be expected to have an understanding of the mechanism of action, to recognize the appropriate indications, to know the appropriate route of administration, to know specific drug doses to identify dangerously inappropriate doses of very commonly used drugs, the important contraindications and potential adverse reactions and interactions, to know how to monitor the drug's beneficial and harmful effects and to be able to explain the salient features of all the above to the patient.

Pharmacotherapy is the academic discipline that supports adequate practice of pharmaceutical care. Pharmacotherapy is usually taught as lectures in pharmacy schools and many students have a difficulty in implementing the theoretical knowledge into practice. ${ }^{6}$ Nowadays there is a general agreement that this area of undergraduate education needs to be strengthened. ${ }^{7}$

The successful delivery of pharmacotherapy learning would involve a variety of learning styles, but the content should, as far as possible, be centered on inquisitive rather than passive learning, including opportunities for self-directed learning. Various implementations of the active-learning approach have been used to teach pharmacotherapeutic topics. ${ }^{8-11}$

Self-directed learning is a method of organizing teaching and learning in which the learning tasks are largely within the learners' control. It can also be viewed as a goal towards which learners strive so that they become empowered to accept personal responsibility for their own learning, personal autonomy, and individual choice. $^{12}$

Philip Candy identified in the literature about 100 traits associated with self-direction, which he synthesized as the ability to be methodical and disciplined; logical and analytical; collaborative and interdependent; curious, open, creative, and motivated; persistent and responsible; confident and competent at learning; and reflective and self-aware. ${ }^{13}$

Gaining pharmacotherapy knowledge and at the same time applying this knowledge in practice is essential for learning in general and, presumably, also for the development of patient-centered care by pharmacy students. ${ }^{14-16}$ Therefore, storing pharmacotherapeutic knowledge in combination with the situation in which this knowledge will be applied benefits the speed and quality with which the information is recalled. ${ }^{17}$

Therefore, we designed and implemented a self-directed learning to guide pharmacotherapy study which was held in the second semester of the fifth year during the APPE.

This study describes implementation of a self-assessment exercise, assessment of students' performance and mastery of learning objectives, and student perceptions.

\section{MATERIALS AND METHODS}

Study participants included 62 students in the fifth year of the degree in pharmacy during a 6-month APPE.

Thirty two students who completed their APPE from January 2012 through June 2012 were assigned to the intervention group (made the exercise during the training), and the other thirty who completed their APPE from July 2012 through December 2012 were assigned to control group (did not make the exercise during the training)

Students in the intervention group checked their own knowledge about: generic name, drug class, indication, dosage, potential adverse reactions and interactions, of 10 prescription drugs per week, during six months of practical training. Students completed a self-assessment of their level of knowledge of prescription drugs using an answer sheet (Table 1). Each student completed a self-assessment of his level of knowledge of 240 prescription drugs.

\section{Effectiveness of intervention}

To test previous students' knowledge of pharmacotherapy, they completed a multiple-choice pre-test. After six months of practical training, carrying out the self- 
assessment exercise, students completed a post-test. The 50-question pre and post-tests were scored, with 0.2 points given for each correct response, so that the highest possible score was 10. Each student received a unique identifying number that allowed for anonymous testing but subsequent comparison of pre- and postintervention scores.

The average response to each individual pre-intervention test was compared to the average response to each post-test. Besides, a comparison of the average preand post-intervention test scores between intervention group and the control group was measured.

Test scores were analyzed using independent $t$ tests at the 0.05 level of significance.

\section{Student pharmacotherapy learning development}

Student learning development was measured as the percentage of correct answers, related to students' level of pharmacotherapy knowledge, filled out using the answer sheet, in the course of the 6 months of practical training.

Answer sheet design allows knowing the students' level of knowledge of prescription drugs, about: drug class, indication, dosage, potential adverse reactions and interactions, given the brand name or the generic name.

Eight student's answer sheets were analyzed to know the improvement of student pharmacotherapy learning during the APPE. Six exercises from community pharmacy and two from hospital pharmacy, according to the percentage of training carried out in both types of practical settings. Altogether, 1920 medical prescriptions were studied.
Chi-square test and Fisher's exact test were used to compare the percentages between the beginning and the end of the six-months of practical training.

\section{Commonly prescription drug list}

The analysis of 8 student's answer sheets allowed us the identification of commonly prescription drugs, both in community pharmacy and hospital pharmacy. The final list comprises the drugs meaning the $30 \%$ of the most commonly prescribed.

\section{Student's satisfaction}

After the training, students in the intervention group were asked to complete an anonymous questionnaire regarding their impressions and satisfaction about the self-assessment exercise.

The survey instrument contains the following items that are rated on a 5 point scale: (1) indicate the degree to which you feel this exercise improved your pharmacotherapy learning; (2) indicate about the time spent on exercise during practical training; (3) indicate the workload involved this exercise during the practical training; (4) indicate the degree to which you feel this exercise caused motivation for professional improvement.

The students were also asked to provide a written reply on what they liked most about this learning experience, what they liked least and any general comments.

\section{Statistical analysis}

Analyses were performed using SPSS, Version 15.0 (SPSS, Inc., Chicago IL).

\begin{tabular}{|c|c|c|c|c|c|c|}
\hline Student & Name & Surname & 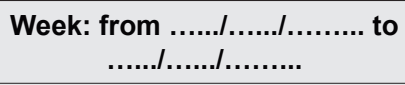 & & & \\
\hline PRESCRIPTION & $\begin{array}{c}\text { Generic } \\
\text { name }\end{array}$ & Drug class & Indication & Dosage & $\begin{array}{l}\text { Adverse } \\
\text { reactions }\end{array}$ & Interactions \\
\hline & & & & & & \\
\hline & & & & & & \\
\hline & & & & & & \\
\hline & & & & & & \\
\hline & & & & & & \\
\hline & & & & & & \\
\hline & & & & & & \\
\hline & & & & & & \\
\hline & & & & & & \\
\hline & & & & & & \\
\hline & & & & & & \\
\hline & & & & & & \\
\hline
\end{tabular}


Table 2: Comparison of the average pre-test and post-test scores between intervention group and the control group.

\begin{tabular}{|l|c|c|c|}
\hline \multirow{2}{*}{} & \multicolumn{2}{|c|}{ Score } \\
\cline { 2 - 4 } & $\begin{array}{c}\text { Average (SD) Intervention } \\
(\mathbf{n = 3 2})\end{array}$ & $\begin{array}{c}\text { Average (SD) } \\
\text { Control (n=30) }\end{array}$ & $p$ \\
\hline Pre test & $1.99(0.93)$ & $1.59(0.90)$ & 0.095 \\
\hline Post test & $4.58(1.37)$ & $3.06(1.50)$ & $<0.001$ \\
\hline Change score & $2.59(1.30)$ & $1.46(1.36)$ & 0.001 \\
\hline
\end{tabular}

SD: Standard Deviation : $\mathrm{P}=$ level of significance

\section{RESULTS}

\section{Effectiveness of intervention}

Table 2 includes pre- and post-intervention tests scores on pharmacotherapy knowledge, for intervention and control groups. Pre-test results for intervention and control groups were comparable, with average scores of 1.99 and 1.59 , respectively. A two-tailed t test revealed no significant difference $(\mathrm{p}>0.05)$ among the averages of the 2 groups at the pre-intervention stage. After the six months-long APPE, however, the average test scores of those who used the learning exercise increased notably over those of the control group. The average score of students in the control group was 3.06 while the intervention group's average score was 4.58 , a difference of 1.52 points on a 10 -point scale $(\mathrm{p}<0.001)$.

\section{Student pharmacotherapy learning development}

Data shown come from the analysis of 8 student answer sheets. Figure 1 shows the percentage of correct answer about: generic name, drug class, indication, dosage, potential adverse reactions, and interactions, filled out by students given the brand name of prescriptions, in the course of the 6 months of practical training.

The percentage of correct answer, filled out given the knowledge of the generic name of prescription drugs, is shown in Figure 2. In both figures, results showed an increment of pharmacotherapy learning during six months. There was a statistically significance difference between the first and the last month of practical training for all areas of pharmacotherapeutic knowledge $(\mathrm{p}<0.05)$.

"Indication" and "drug class" displayed the biggest percentage of correct answer in the first month, while "dosage", "adverse reactions" and "interactions" showed the least percentage of correct answer at this time.

\section{Commonly prescription drug list}

Analysis of 8 student answer sheets produced the following results.

The most commonly used prescription drugs are listed in Table 3. The list included, twenty one drugs meaning the $30 \%$ of the most commonly prescription drugs used in community pharmacy, and sixteen meaning the 30\% of the most commonly prescription drugs used in hospital pharmacy. The three drugs that rose into the top of the list were lorazepam, omeprazole, and paracetamol in community pharmacy and, dipyrone, paracetamol and pantoprazole in hospital pharmacy. In both, benzodiazepines and proton pump inhibitors were the most commonly prescription drug classes according to Anatomical Therapeutic Chemical (ATC) classification system (Table 4).

\section{Students' satisfaction}

Table 5 summarizes the fifth-year students' response to each question on the survey instrument. A majority of students felt that the self-assessment exercise improved their pharmacotherapy learning, in the course of the 6 months of practical training (84.4\% agreed or strongly agreed).

The number of hours spent each week on pharmacotherapy self-assessment exercise ranged between 1 and 4. All students expressed that both the time spent on exercise and the workload involved during practical training were adequate.

Nearly all the students felt this self-assessment exercise enhanced their motivation for professional development $(90.6 \%$ agreed or strongly agreed).

Many students provided additional comments, such as: "An interesting learning method because it encourages you to want to learn"; "Important to familiarize oneself with the most commonly prescription drugs"; "I am now aware of the importance of continuous education"; "Learn how to learn", "Better understanding of common prescription drugs"; "Self-assessment encourages students to reflect on their knowledge and learning".

\section{DISCUSSION}

During six months of practical training, fifth-year pharmacy students realize of the core learning outcomes, including knowledge of and understanding about medicines and skills necessary to competently practice pharmacy. They feel overwhelmed by the large number of 


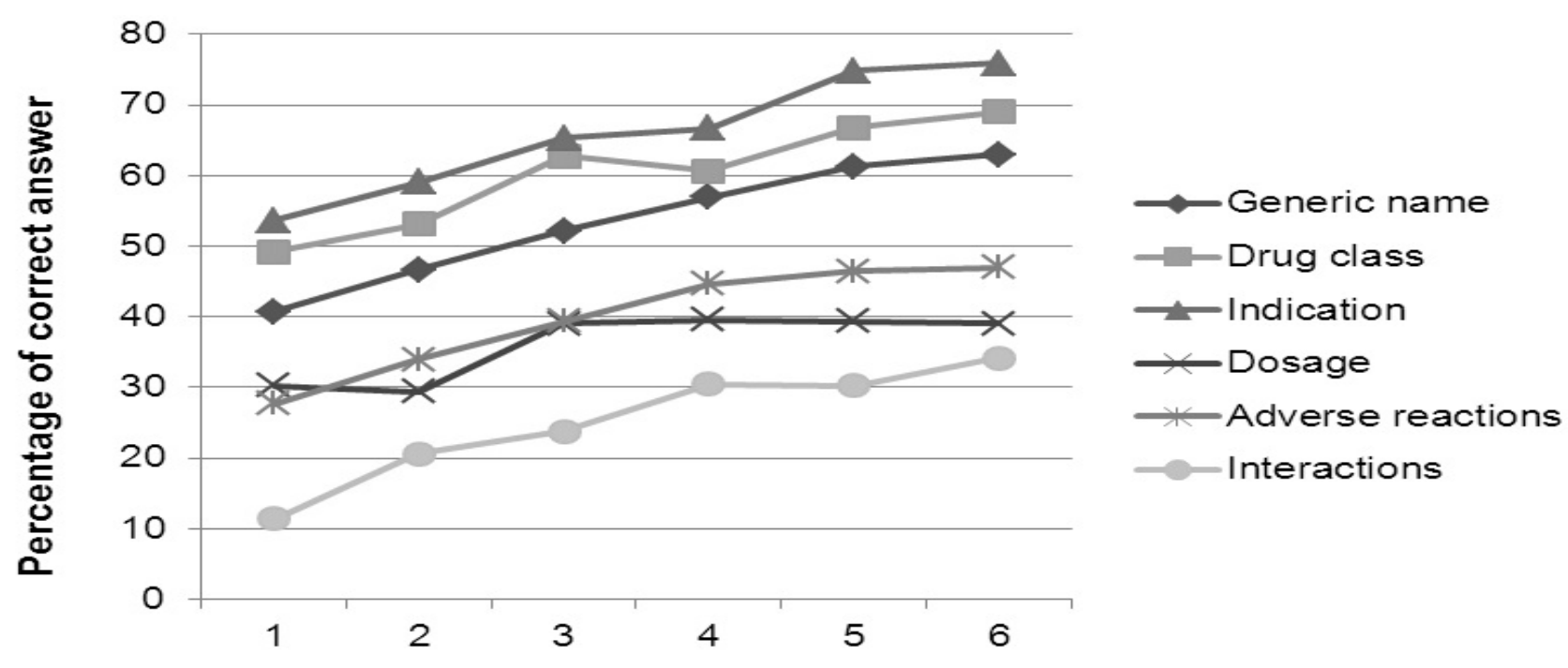

Time (months)

Figure 1: Percentage of correct answers filled out by students given the brand name of prescription drugs, during the six months of practical training

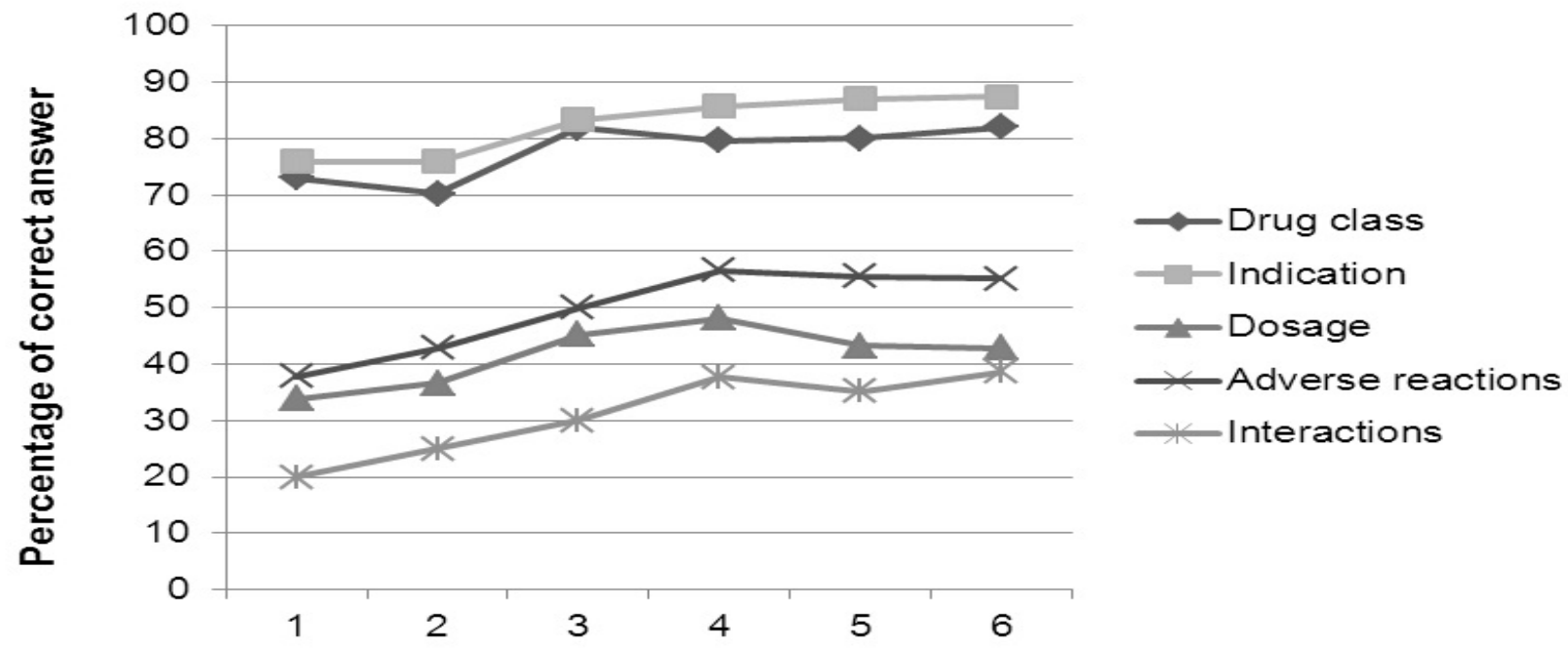

Time (months)

Figure 2: Percentage of correct answers filled out by students given the generic name of prescription drugs, during the six months of practical training

different prescription and non-prescription drugs used, and they think that the learning regarding the therapeutic use of drugs has not been covered enough in the Pharmacy degree curriculum prior to enrolling in the APPE. ${ }^{18-20}$

Traditionally in Spain, pharmacotherapy is taught within a lecture-based course in the fourth and fifth year of the degree of pharmacy curriculum. Large, lecture-based courses create a bulimic learning environment, wherein students memorize a vast amount of information with little long-term retention of the knowledge and skills necessary to competently practice pharmacy. ${ }^{20}$
In accordance with this fact, self-directed pharmacotherapy learning was provided to fifth-year pharmacy students during APPE, expecting to facilitate the learning outcomes and to increase students' responsibility for their own learning regarding drug therapy.

To test students' knowledge of pharmacotherapy prior the exercise, provided during the APPE, they completed a 50 multiple-choice questions. The low average score on pre-test (1.99 out of 10) suggests that the didactic portion of the pharmacy curriculum alone does not result in a full understanding about medicines, to com- 
Table 3: Drugs meaning the $30 \%$ of the most commonly prescribe drugs both in community and hospital practical settings.

\begin{tabular}{|l|c|c|c|}
\hline \multicolumn{1}{|c|}{ Drug } & Community (\%) $\mathbf{n = 1 2 0 0}$ & Drug & $\begin{array}{c}\text { Hospital (\%) } \\
\mathbf{n = 7 2 0}\end{array}$ \\
\hline Lorazepam & & & 3.8 \\
\hline Omeprazole & 2.5 & Dipyrone & 3.6 \\
\hline Paracetamol & 2.1 & Paracetamol & 3.5 \\
\hline Acetylsalicylic acid & 2.1 & Pantoprazole & 2.7 \\
\hline Acetaminophen & 1.9 & Enoxaparin & 2.2 \\
\hline Diclofenac & 1.9 & Lorazepam & 2.0 \\
\hline Simvastatin & 1.7 & Furosemide & 1.7 \\
\hline Atorvastatin & 1.6 & Omeprazole & 1.4 \\
\hline Paroxetine & 1.5 & Amoxicillin-Clavulanic Acid & 1.4 \\
\hline Dipyrone & 1.5 & Lormetazepam & 1.3 \\
\hline Enalapril & 1.4 & Haloperidol & 1.3 \\
\hline Bromazepam & 1.4 & Enalapril & 1.3 \\
\hline Lansoprazole & 1.4 & Bromazepam & 1.1 \\
\hline Acetylcysteine & 1.3 & Levothyroxine & 1.1 \\
\hline Meformin & 1.2 & Diazepam & 1.1 \\
\hline Levothyroxine & 1.0 & Digoxin & 1.1 \\
\hline Fluoxetine & 1.0 & Ondansetron & - \\
\hline Tramadol-Paracetamol & 1.0 & - & - \\
\hline Pantoprazole & 1.0 & - & - \\
\hline Calcium-vitamin D & 1.0 & - & - \\
\hline Amoxicillin & 1.0 & - & - \\
\hline Total & 0.9 & - & 30.6 \\
\hline & 30.4 & & \\
\hline & & - & \\
\hline
\end{tabular}

\section{Table 4: Drug class (ATC classification) meaning the $30 \%$ of the most commonly prescribes drugs both in com-} munity and hospital practical settings.

\begin{tabular}{|c|c|c|c|c|c|}
\hline ATC & Drug class & $\begin{array}{c}\text { Community (\%) } \\
n=1200\end{array}$ & ATC & Drug class & $\begin{array}{c}\text { Hospital (\%) } \\
n=720\end{array}$ \\
\hline N05BA & $\begin{array}{c}\text { Benzodiazepine } \\
\text { derivatives }\end{array}$ & 6.8 & N05BA & $\begin{array}{l}\text { Benzodiazepine } \\
\text { derivatives }\end{array}$ & 5.7 \\
\hline A02BC & $\begin{array}{l}\text { Proton pump } \\
\text { inhibitors }\end{array}$ & 4.8 & A02BC & Proton pump inhibitors & 5.5 \\
\hline C10AA & $\begin{array}{c}\text { HMG CoA reductase } \\
\text { inhibitors }\end{array}$ & 4.7 & N02BB & Pyrazolones & 3.8 \\
\hline N06AB & $\begin{array}{l}\text { Selective serotonin } \\
\text { reuptake inhibitors }\end{array}$ & 3.4 & N02BE & Anilides & 3.6 \\
\hline B01AC & $\begin{array}{c}\text { Platelet aggregation } \\
\text { inhibitors excluding } \\
\text { heparin }\end{array}$ & 3.1 & $\mathrm{~B} 01 \mathrm{AB}$ & Heparin group & 3.4 \\
\hline M01AE & $\begin{array}{c}\text { Propionic acid } \\
\text { derivatives }\end{array}$ & 2.9 & $\mathrm{H} 02 \mathrm{AB}$ & Glucocorticoids & 2.9 \\
\hline M01AB & $\begin{array}{c}\text { Acetic acid } \\
\text { derivatives and } \\
\text { related substances }\end{array}$ & 2.6 & C03CA & Sulfonamides, plain & 2.4 \\
\hline N02BE & Anilides & 2.3 & N06AX & Other antidepressants. & 2.1 \\
\hline Total & & 30.6 & - & - & 29.4 \\
\hline
\end{tabular}

ATC: Anatomical Therapeutic Chemical classification 


\begin{tabular}{|c|c|c|c|c|c|}
\hline \multirow[b]{2}{*}{ Statements } & \multicolumn{5}{|c|}{ Student response $\mathrm{n}(\%)$} \\
\hline & 1 & 2 & 3 & 4 & 5 \\
\hline $\begin{array}{l}\text { I feel this exercise improved my } \\
\text { pharmacotherapy learning }\end{array}$ & $0(0)$ & $2(6.2)$ & $3(9.4)$ & $8(25)$ & $19(59.4)$ \\
\hline $\begin{array}{l}\text { Time student spent on exercise during practical } \\
\text { training was adequate }\end{array}$ & $0(0)$ & $0(0)$ & $0(0)$ & $13(40.6)$ & $19(59.4)$ \\
\hline $\begin{array}{l}\text { Student workload involved this exercise during } \\
\text { practical training was adequate }\end{array}$ & $0(0)$ & $0(0)$ & $0(0)$ & $8(25)$ & $24(75)$ \\
\hline $\begin{array}{l}\text { I feel this exercise caused motivation for my } \\
\text { professional improvement }\end{array}$ & $0(0)$ & $0(0)$ & $3(9.4)$ & $11(34.4)$ & $18(56.2)$ \\
\hline
\end{tabular}

Responses were based on a Likert scale ranging from $1=$ strongly disagree to $5=$ strongly agree

petently practice of pharmaceutical care. This fact demonstrated a need to improve pharmacotherapy learning. After the practical training, students completed an identical test to assess the impact on student pharmacotherapy learning. The average score on the post-test was 4.58 . The average change score (post-test minus pre-test) was $2.59 \pm 1.30$. The exercise was effective in increasing student knowledge of pharmacotherapy, during APPE. To determine whether this objective was met, the status quo of learning (without exercise) was observed. There was not a significant difference $(p>0.05)$ in pre-test scores between control and intervention groups. However, the average post-test scores of those who used the learning exercise increased notably over those of the control group. A difference of 1.52 points on a 10 -point scale $(\mathrm{p}<0.001)$ was found. The authors demonstrated improvement between the intervention and control students' pharmacotherapy knowledge, during their APPE.

By the other hand, our results indicate that multiplechoice questions do not reflect to a large extent the drugs studied by the students during the six months of practical training, both in community and hospital settings.

The analysis of 8 answer sheets allowed us to obtain a list comprised prescription drugs, commonly used in treating common illnesses. The list is raised as an educational tool for subsequent courses, prior to enrolling in the APPE, by prioritizing learning around a core list of commonly prescription drugs that students would be expected to know in detail, and by offering students a realistic and achievable learning target. Besides, the list of commonly used drugs obtained from this work will allow us to design a test focused on the actual practice of the students, and thus more accurately measure the learning development during the APPE.

Besides, our results showed an important student pharmacotherapy learning development during the APPE. The analysis of 8 student answer sheets demonstrated higher levels of knowledge about mechanism of action, drug class and indications at the beginning of the practical training. However the knowledge necessary to know how to monitor the drug's beneficial and harmful effects and to be able to explain the salient features of all the above to the patient showed the least percentage of correct answer during the practical training. Results showed that actually teaching therapeutics is not focused on practice pharmacy.

This finding and the large positive reception of the selfdirected pharmacotherapy exercise illustrates the feasibility and usefulness of this self-assessment method. This method allows the student to achieve a greater knowledge of drugs in the practice over time, an important knowledge in the professional work of pharmaceutical care. Finally, this method also helps to develop some skills as lifelong learning or responsibility because the student can identify his deficiencies and to be aware of the necessity of lifelong learning.

\section{CONCLUSION}

Self-directed pharmacotherapy learning was successfully implemented. This learning method allows the student to achieve a greater knowledge of drugs in the practice over time, an important knowledge in the professional work of pharmaceutical care.

This teaching tool to guide pharmacotherapy selfdirected learning could be applied to other courses and at other pharmacy schools. This method also helps to develop some skills as lifelong learning or responsibility because the student can identify his deficiencies and to be aware of the necessity of lifelong learning.

By integrating the knowledge and skills, we hope that the students will be able to acquire abilities in therapeutics when they become pharmacists.

\section{ACKNOWLEDGEMENTS}

The authors would like to thank the pharmacy students for their participation in this study. 


\section{REFERENCES}

1. Hepler CD, Strand LM. Opportunities and responsibilities in pharmaceutical care. Am J Hosp Pharm. 1990; 47(3): 533-43.

2. Wallman A, Lindblad AK, Gustavsson M, Ring L. Factors associated with reflection among students after an advanced pharmacy practice experience (APPE) in sweden. Am J Pharm Educ. 2009; 73(6): 107.

3. Wallman A, Sporrong SK, Gustavsson M, Lindblad AK, Johansson M, Ring L. Swedish students' and preceptors' perceptions of what students learn in a six-month advanced pharmacy practice experience. Am J Pharm Educ. 2011; 75(10): 197

4. Cheng JW. A cardiovascular pharmacotherapy elective course to enhance pharmacy students' literature evaluation skills and ability to apply clinical evidence. Am J Pharm Educ. 2012; 76(7): 137.

5. Moczygemba LR, Goode JV, Silvester JA, Matzke GR. Pharmacy practice in Virginia in 2011. Ann Pharmacother. 2012; 46(4): S13-26.

6. Toklu HZ. Problem based pharmacotherapy teaching for pharmacy students and pharmacists. Curr Drug Deliv. 2013; 10(1): 67-70.

7. Echizen H. Toward pharmacotherapy management by pharmacists: A point of view by a teacher in a private pharmaceutical university. Yakugaku Zasshi. 2007; 127(2): 227-30.

8. Estus EL, Hume AL, Owens NJ. An active-learning course model to teach pharmacotherapy in geriatrics. Am J Pharm Educ. 2010; 74(3): 38.

9. Stewart DW, Brown SD, Clavier CW, Wyatt J. Active-learning processes used in US pharmacy education. Am J Pharm Educ. 2011; 75(4): 68

10. Elliott JP, Koerner PH, Heasley J, Kamal KM. The impact of elective activelearning courses in pregnancy/lactation and pediatric pharmacotherapy. Am J Pharm Educ. 2012; 76(2): 26.
11. Hidayat L, Patel S, Veltri K. Active-learning implementation in an advanced elective course on infectious diseases. Am J Pharm Educ. 2012; 76(5): 87.

12. Kaufman DM. Applying educational theory in practice. BMJ. 2003; 326(7382): 213-6.

13. Candy P. Self-Direction for Lifelong Learning: A Comprehensive Guide to Theory and Practice. San Francisco, CA: Jossey-Bass; 1991.

14. Flowers SK, Vanderbush RE, Hastings JK, West D. Web-based multimedia vignettes in advanced community pharmacy practice experiences. Am J Pharm Educ. 2010; 74(3): 39.

15. Barclay SM, Jeffres MN, Bhakta R. Educational card games to teach pharmacotherapeutics in an advanced pharmacy practice experience. Am J Pharm Educ. 2011; 75(2): 33.

16. Hata M, Klotz R, Sylvies R, et al. Medication therapy management services provided by student pharmacists. Am J Pharm Educ. 2012; 76(3): 51.

17. Richir MC, Tichelaar J, Geijteman EC, de Vries TP. Teaching clinical pharmacology and therapeutics with an emphasis on the therapeutic reasoning of undergraduate medical students. Eur J Clin Pharmacol. 2008; 64(2): 217-24.

18. Ried LD, Brazeau GA, Kimberlin C, Meldrum M, McKenzie M. Students' perceptions of their preparation to provide pharmaceutical care. Am J Pharm Educ. 2002; 66(4): 347-56.

19. Hogan S, Lundquist LM. The impact of problem-based learning on students perceptions of preparedness for advanced pharmacy practice experiences. Am J Pharm Educ. 2006; 70(4): 82.

20. Zorek JA, Sprague JE, Popovich NG. Bulimic learning. Am J Pharm Educ. 2010; 74(8): 157. 